Supplement of The Cryosphere, 11, 1387-1402, 2017

https://doi.org/10.5194/tc-11-1387-2017-supplement

(C) Author(s) 2017. This work is distributed under

the Creative Commons Attribution 3.0 License.

(c) (1)

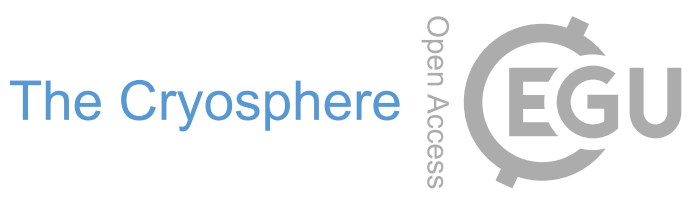

Supplement of

\title{
Impacts of freshwater changes on Antarctic sea ice in an eddy-permitting sea-ice-ocean model
}

Verena Haid et al.

Correspondence to: Verena Haid (v.haid@web.de)

The copyright of individual parts of the supplement might differ from the CC BY 3.0 License. 


\section{$\underline{\text { S1 Model validation }}$}

Here, we present results from the control run (CTR) to give an overview over the model's performance. We compare our results to observations of sea ice (Cavalieri et al., 1996) and ocean temperature and salinity (Orsi and Whitworth, 2005). For the sea ice characteristics, the main focus is on the last decade (2004-2013), since it is used for the analysis of the main article. For the water characteristics, we use model data from the same year as the observation.

\section{S1.1 Sea ice characteristics}

The modeled sea ice concentration around Antarctica is compared with data obtained from passive microwave data sensors (Cavalieri et al., 1996) in Fig. S.la-d. The modelled ice concentration successfully reproduces the spatial distribution for both the minimum sea ice extent in March and the maximum sea ice extent in September.

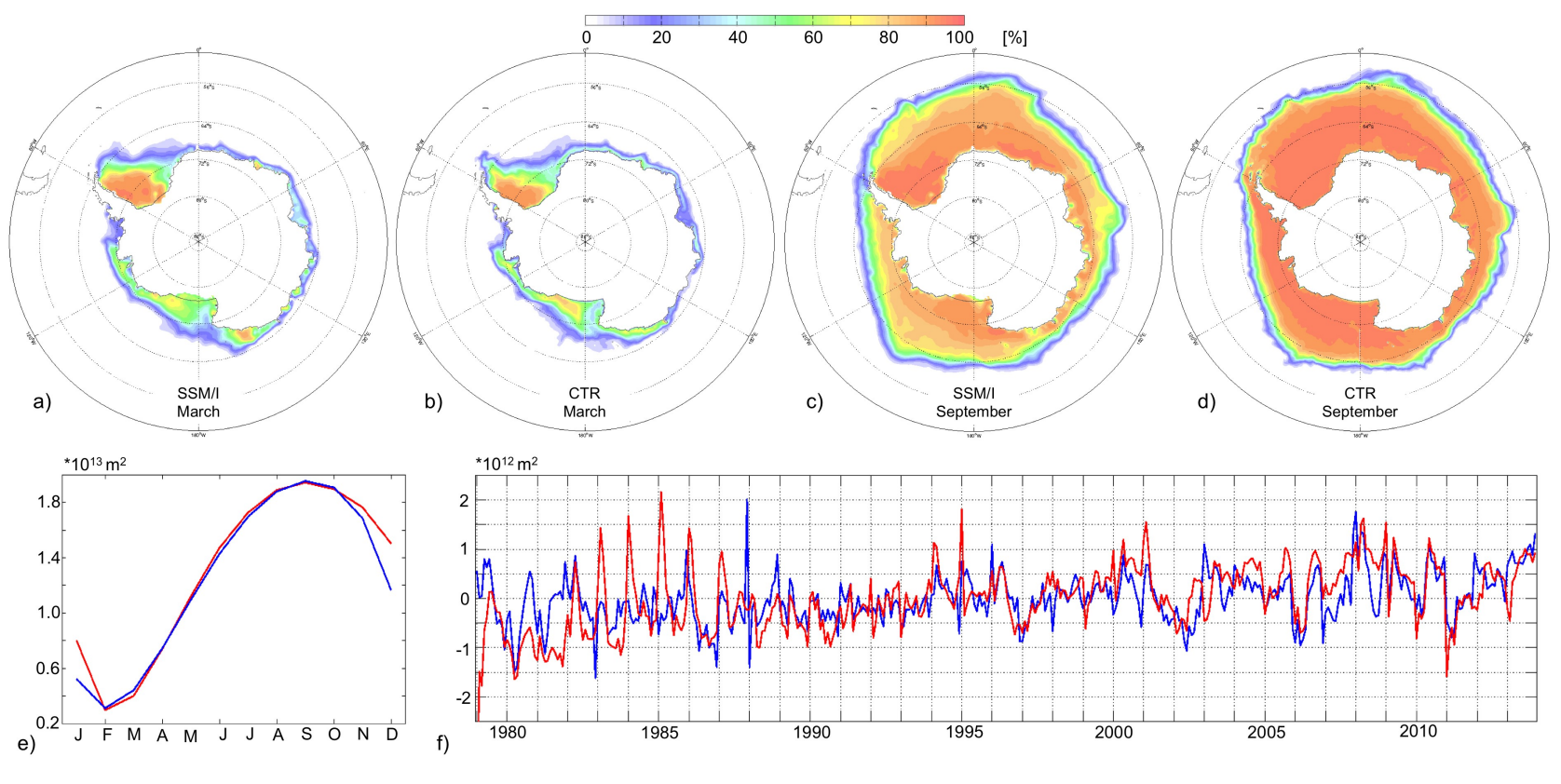

Figure S.1: a-d) Sea ice concentrations, mean 2004-2013; e) mean seasonal cycle of sea ice extent 19792013 and f) divergence from mean seasonal cycle of sea ice extent, SSM/I observations (blue) and CTR (red).

In September, the model features a sea ice outline that matches the observed shape very well, while the sea ice concentrations are slightly overestimated. The confines of the sea ice covered area in winter are defined by the Antarctic circumpolar current (ACC). The warm surface temperatures of the ACC melt the ice and thus inhibit sea ice expansion. The larger discrepancies between model and observation can therefore be mainly attributed to the resolution of the bathymetry, which steers the ocean currents.

The mean seasonal cycle of both, simulated and observed sea ice extent (Fig. S.1e), calculated from the sea ice concentration data using a threshold of $15 \%$, shows that the model very well captures amplitude and range of the seasonal changes. The extremes in summer and winter are very close to the observations and also during the freezing period, the simulated sea ice extent does not differ far from the observations. Only during the melting season, the simulation features a higher sea ice extent than observed.

A time series of the deviations of the sea ice extent from the mean seasonal cycle (Fig. S.1f) features periods of large discrepancies due to the spin-up in the first decade. Hereafter, the differences between model and observations in the sea ice extent are small and the anomalies of the sea ice extent show similar variability in both, model and satellite observations. 

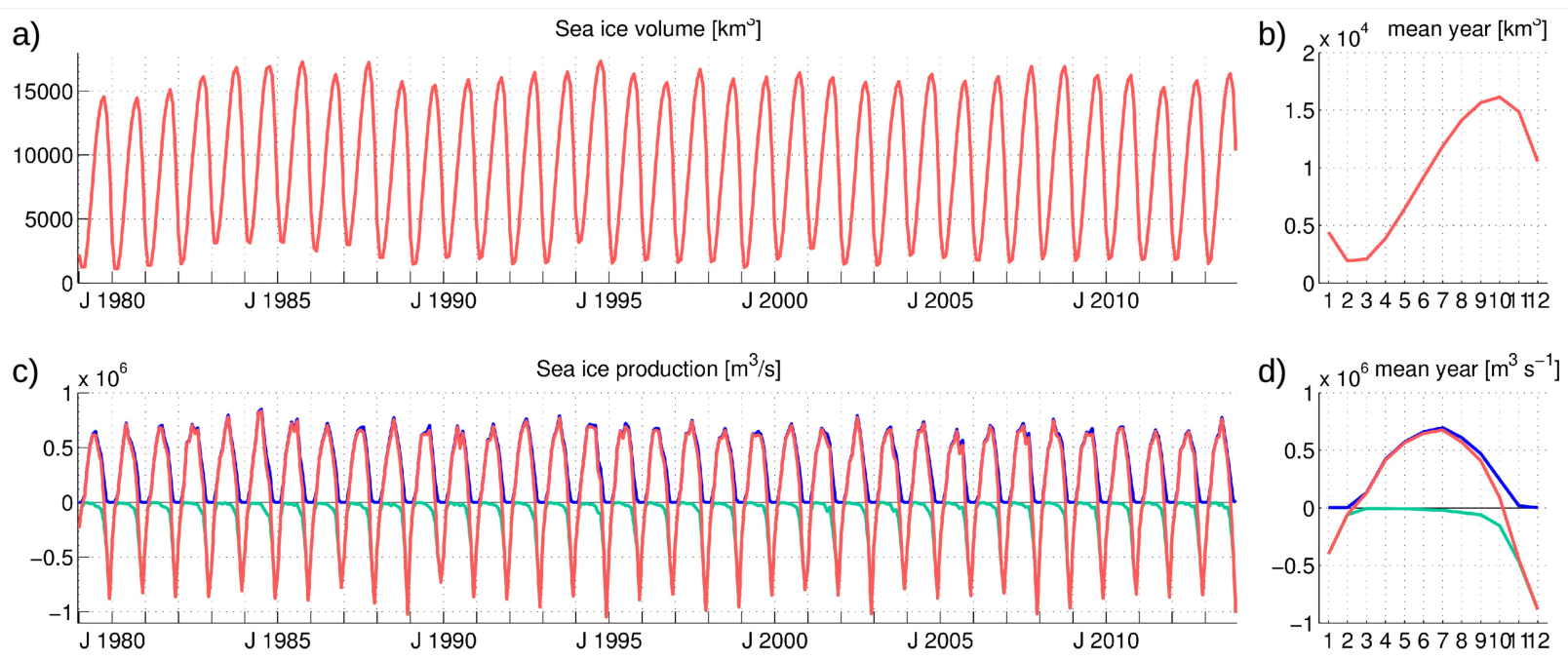

Figure S.2: a) Sea ice volume 1979-2013, b) its mean seasonal cycle, c) sea ice formation (dark blue), sea ice melt (light blue) and their sum (red) 1979-2013 and d) their mean seasonal cycle in CTR.

The sea ice volume in CTR (Fig. S.2a,b) features a reasonable amplitude in its seasonal cycle and in the last two decades the interannual variations show no obvious drift and are within a realistic range. Similarly, the ice production in CTR (Fig. S.2c,d) features interannual variations within a reasonable range, but no strong trends after the initial decade.

The model's sea ice thickness (Fig. S.3a) features a pattern in agreement with expectations. with the highest sea ice thicknesses close to the continent, while the areas farther offshore are covered with thinner ice. In the Weddell Sea the thickest sea ice is found close to the Antarctic Peninsula and in the Ross Sea, we can see the northward transport of the sea ice leaving traces in the thickness distribution.

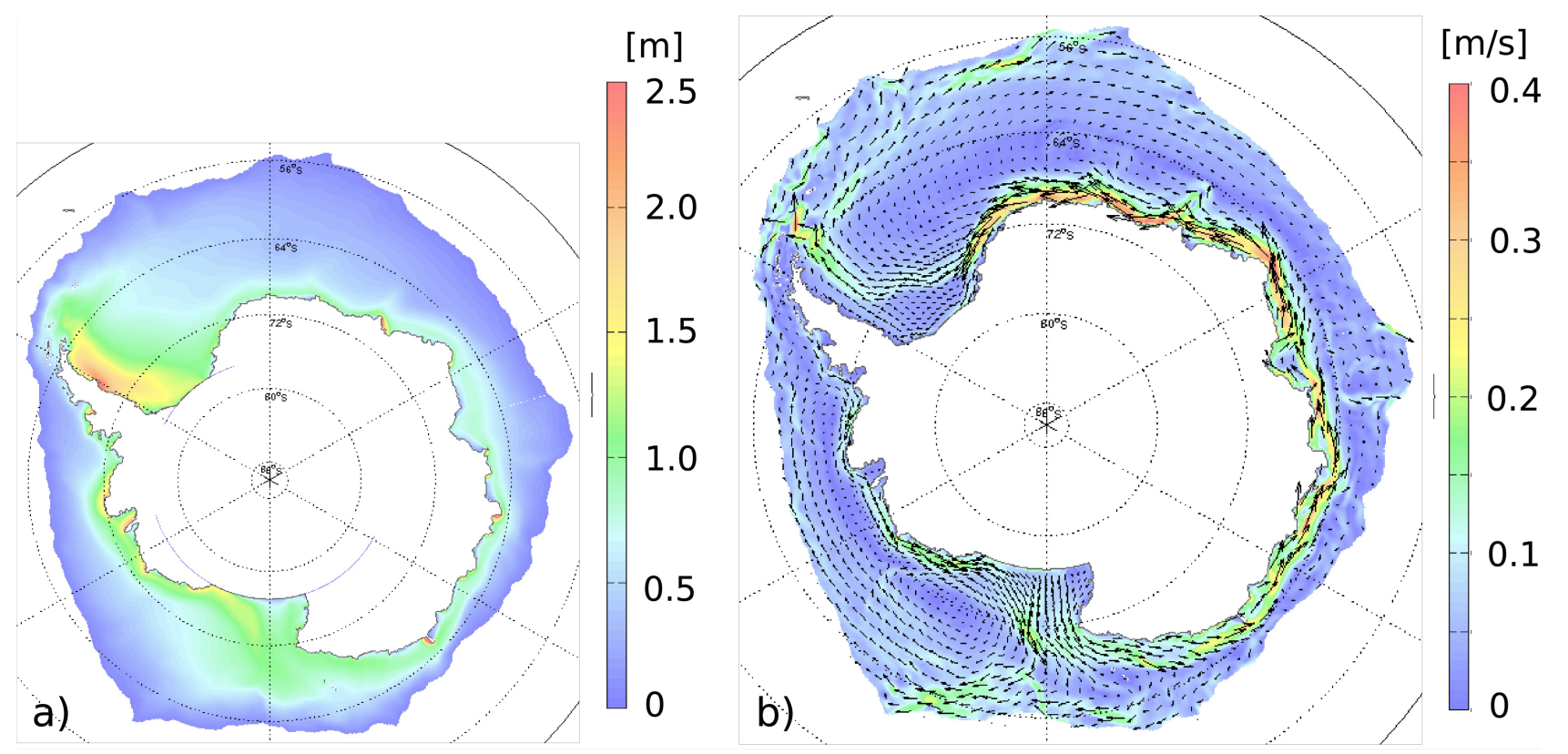

Figure S.3: a) Mean sea ice thickness in CTR, April-September 2004-2013. b) Mean sea ice velocity in CTR, April-September 2004-2013. 
The long-term mean sea ice velocities (Fig. S.3b) are strongly influenced by the ocean surface velocities. We find westward drift close to the coastline, northward drift associated with the subpolar gyres in the Weddell and the Ross Seas, and eastward drift offshore, under the influence of the northern branches of the gyres and the Antarctic Circumpolar Current.

\section{S1.2 Water characteristics}

In this section, salinity and potential temperature of the model are compared to observations (World Ocean Circulation Experiment, Orsi and Whitworth, 2005) along two vertical sections through the Weddell Sea (WOCE section A23) and the Ross Sea (WOCE section P16). The observations were taken during 1995 and 1992, respectively, and are compared to the annual mean of the corresponding year from the simulation.

The comparison of salinity and temperature in the Weddell Sea (Fig. S.4) shows, that the model performs very well in reproducing the general characteristics of the different water masses. The simulation slightly overestimates the temperature and salinity maximum of the WDW, which can be attributed to the fact that the coarser model topography allows the waters of the ACC to mix more easily with those of the gyre over the South Scotia Ridge. Also the bottom water in the Weddell Basin is slightly warmer and more saline in the simulation than observed.

Deficiencies in the topography of the South Scotia Ridge let the dense water escape more easily into the open ocean in the simulation. Furthermore, it is a common problem for OGCMs to correctly reproduce the formation of bottom water.
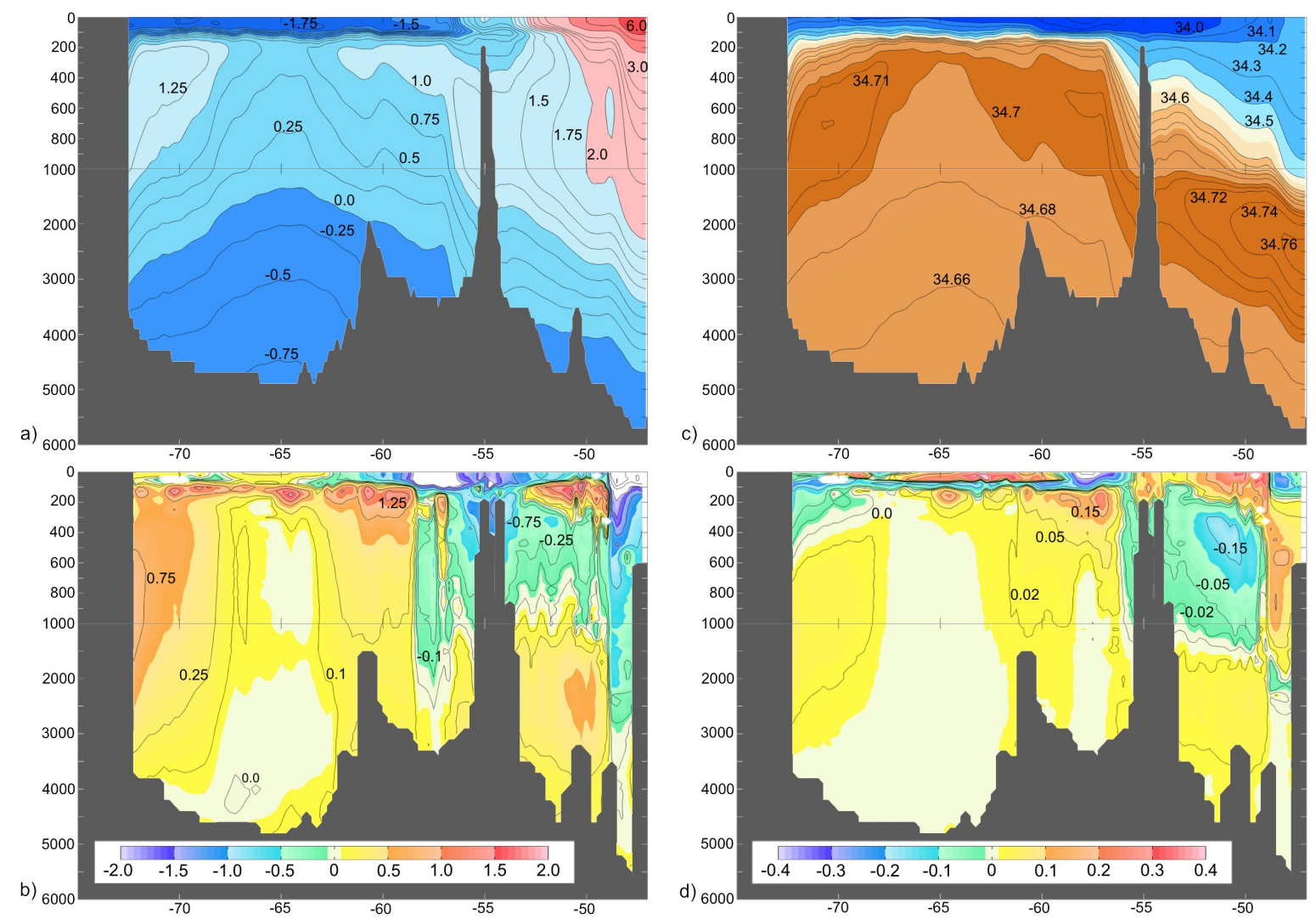

Figure S.4: Section through the Weddell Sea (WOCE A23). a) CTR pot. temperature, b) difference to observed pot. temperature (Orsi and Whitworth, 2005), c) CTR salinity, d) difference to observed salinity (Orsi and Whitworth, 2005). 

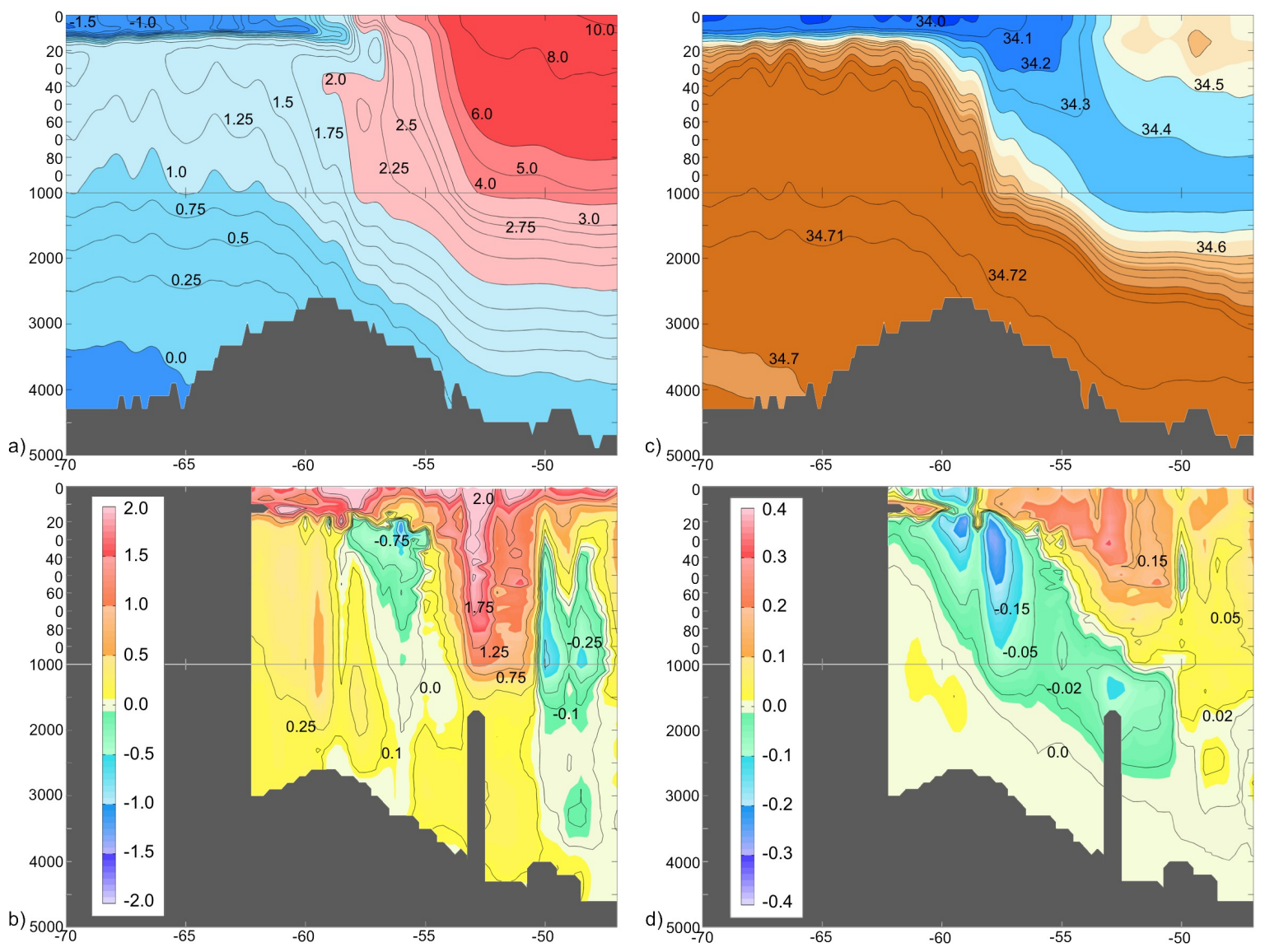

Figure S.5: Section at $150^{\circ} \mathrm{W}$ (WOCE P16). a) CTR pot. temperature, b) difference to observed pot. temperature (Orsi and Whitworth, 2005), c) CTR salinity, d) difference to observed salinity (Orsi and Whitworth, 2005).

At the WOCE section P16 in the eastern Ross Sea at $150^{\circ} \mathrm{W}$, both temperature and salinity show very good agreement between model and observation (Fig. S.5). In the simulation, the bottom waters retained in the southern basin close to the Antarctic continent are slightly warmer and more saline than in the observation. As in the Weddell Sea, the limitations of the model resolution render the bathymetry in the model too coarse, allowing the dense water to escape more easily from the basin, and pose an obstacle for the production of the dense deep waters. 